\title{
Genetic Disorder
}

National Cancer Institute

\section{Source}

National Cancer Institute. Genetic Disorder. NCI Thesaurus. Code C3101.

Genetic diseases are diseases in which inherited genes predispose to increased risk. The genetic disorders associated with cancer often result from an alteration or mutation in a single gene. The diseases range from rare dominant cancer family syndrome to familial tendencies in which low-penetrance genes may interact with other genes or environmental factors to induce cancer. Research may involve clinical, epidemiologic, and laboratory studies of persons, families, and populations at high risk of these disorders. 